
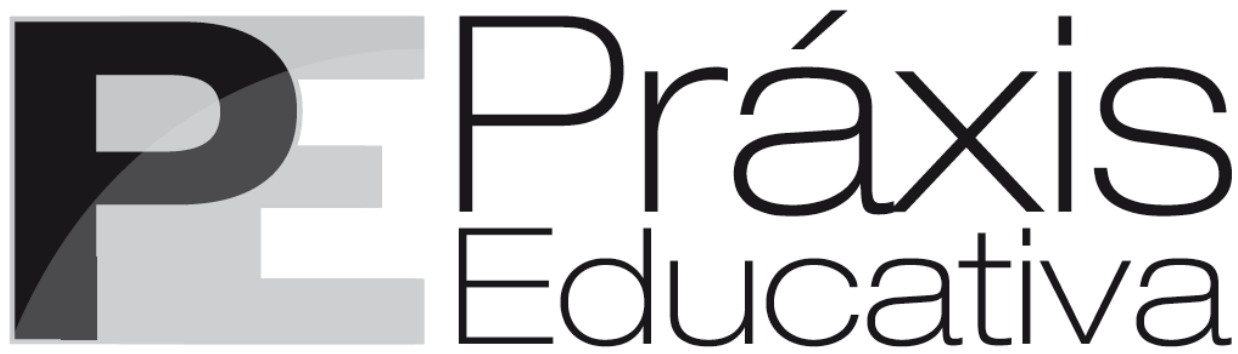

ISSN 1809-4031

elSSN 1809-4309

https://doi.org/10.5212/PraxEduc.v.16.16613.032

\title{
Educação Popular e Pedagogia Crítica: os princípios pedagógicos freireanos na formação de Educadores Populares em Saúde
}

\section{Popular Education and Critical Pedagogy: Freire's pedagogical principles in the training of Popular Health Educators}

\section{Educación Popular y Pedagogía Crítica: los principios pedagógicos de Freire en la formación de Educadores Populares en Salud}

\author{
Fúlvia da Silva Spohr \\ iD https://orcid.org/0000-0002-5069-7462 \\ Mariana Parise Brandalise Dalsotto ${ }^{* *}$ \\ https://orcid.org/0000-0003-4926-6320 \\ Ygor Correa** \\ iD https://orcid.org/0000-0002-3526-9195
}

\begin{abstract}
Resumo: Este artigo, derivado de uma pesquisa qualitativa, apresenta a organização pedagógica de um Curso de Formação e Aperfeiçoamento de Educadores Populares em Saúde no Sistema Único de Saúde (SUS), com vistas a verificar, nesse planejamento, a presença dos princípios da Política Nacional de Educação Popular em Saúde (PNEP-SUS). A PNEP-SUS está fundamentada nas concepções teóricometodológicas da Educação Popular inspiradas na Pedagogia Crítica e na obra de Paulo Freire. A análise realizada identificou os seguintes princípios: Diálogo; Construção compartilhada do conhecimento; Amorosidade; Problematização; Construção do projeto democrático e popular; Convivência não hierarquizada; e Emancipação, os quais orientavam o planejamento das atividades didáticas do curso. $\mathrm{O}$ estudo evidenciou que estratégias de Educação Popular em Saúde, fundamentadas na obra freireana, podem promover a participação popular, a gestão participativa, o exercício do controle social e o cuidado em saúde. Palavras-chave: Educação Popular em Saúde. Paulo Freire. Pedagogia Crítica.
\end{abstract}

Abstract: This article, derived from a qualitative research, presents the pedagogical organization of a Training and Improvement Course for Popular Health Educators in the Unified Health System (Sistema

\footnotetext{
* Universidade Federal de Ciências da Saúde de Porto Alegre (UFCSPA). Doutora em Informática na Educação. Email: <fulvia@ufcspa.edu.br>.

** Universidade de Caxias do Sul (UCS). Doutoranda em Educação. E-mail: <mpbrandalise@ucs.br>.

*** Universidade de Caxias do Sul (UCS). Doutor em Informática na Educação. E-mail: <correaygorprof@gmail.com>.
} 
Educação Popular e Pedagogia Crítica: os princípios pedagógicos freireanos na formação de Educadores...

Unico de Saúde - SUS), in order to verify, in this planning, the presence of the principles of the National Policy on Popular Education in Health (Politica Nacional de Educaşão Popular em Saúde - PNEP-SUS). The PNEP-SUS is based on the theoretical and methodological conceptions of Popular Education inspired by the Critical Pedagogy and Paulo Freire's work. The analysis carried out identified the following principles: Dialogue; Shared construction of knowledge; Lovingness; Problematization; Construction of the democratic and popular design; Non-hierarchical coexistence; and emancipation, which guided the planning of the didactic activities of the course. The study showed that the strategies of the Popular Education in Health, based on Freire's work, can promote popular participation, participatory management, the exercise of social control and health care.

Keywords: Popular Education in Health. Paulo Freire. Critical Pedagogy.

Resumen: Este artículo, derivado de una investigación cualitativa, presenta la organización pedagógica de un Curso de Capacitación y Perfeccionamiento de Educadores Populares en Salud en el Sistema Único de Salud (SUS), con el fin de verificar en esta planificación, la presencia de los principios de la Política Nacional de Educación Popular en Salud (PNEP-SUS). El PNEP-SUS está fundamentado en las concepciones teórico-metodológicas de la Educación Popular inspiradas en la Pedagogía Crítica y en la obra de Paulo Freire. El análisis realizado identificó los siguientes principios: Diálogo; Construcción compartida del conocimiento; Amorosidad; Problematización; Construcción del proyecto democrático y popular; Convivencia no jerarquizada; y Emancipación, los que orientaban la planificación de las actividades didácticas del curso. El estudio evidenció que estrategias de Educación Popular en Salud, fundamentadas en la freireana, pueden promover la participación popular, la gestión participativa, el ejercicio del control social y el cuidado de la salud.

Palabras-clave: Educación Popular en Salud. Paulo Freire. Pedagogía Crítica.

\section{Introdução}

Este estudo apresenta e analisa a organização pedagógica de um Curso de Formação de Educadores Populares em Saúde, no âmbito do Sistema Único de Saúde (SUS) no Brasil, direcionado à formação e ao aperfeiçoamento profissional de equipes de Atenção Básica em Saúde. A motivação para este estudo surgiu a partir da vivência e da trajetória pessoal de uma das autoras deste artigo no processo de implementação da Política Nacional de Educação Popular em Saúde (PNEP-SUS) e em sua participação como educadora em uma das turmas do Curso de Aperfeiçoamento em Educação Popular em Saúde (EdpopSUS 2) ${ }^{1}$, no estado do Rio Grande do Sul, bem como a atuação dos demais pesquisadores alinhadas aos fundamentos teóricometodológicos freireanos.

O curso de formação visa à qualificação da prática educativa dos profissionais da saúde que atuam em territórios com cobertura da Atenção Básica do SUS, o qual reflete criticamente sobre o próprio trabalho em saúde, a partir dos princípios e das ferramentas da Educação Popular (HOLLIDAY, 2006a) e por meio da problematização da realidade, ou seja, da "leitura do mundo" (FREIRE, 1996). O público-alvo do curso são os Agentes Comunitários de Saúde, Agentes de Controle de Endemias, Agentes Indígenas de Saúde servidores ou empregados, vinculados à administração pública direta; profissionais de saúde integrantes da Estratégia de Saúde da Família/Atenção Básica e lideranças comunitárias e integrantes dos movimentos sociais ${ }^{2}$, em atuação no território brasileiro.

O referencial político-pedagógico do Curso de Formação de Educadores Populares em Saúde está apoiado na Pedagogia Crítica (FREIRE, 2005) e foi uma iniciativa do Ministério da

\footnotetext{
1 Para conhecer o Curso de Aperfeiçoamento em Educação Popular em Saúde acesse: http://www.edpopsus.epsjv.fiocruz.br/sobre-o-curso-edpopsus.

2 Indivíduos pertencentes às associações comunitárias, líderes de bairro, etc.
}

Práxis Educativa, Ponta Grossa, v. 16, e2116613, p. 1-19, 2021

Disponível em: <https://www.revistas2.uepg.br/index.php/praxiseducativa> 
Saúde e da Escola Politécnica em Saúde Joaquim Venâncio, da Fundação Oswaldo Cruz para a implementação da PNEP-SUS (BRASIL, 2013). Nesse tocante, este estudo tem por objetivo evidenciar como uma estratégia formativa organizada a partir de um processo de ensino e de aprendizagem dialógico e participativo, fundamentado na Pedagogia Crítica, pode garantir a manutenção de sete princípios preconizados na PNEP-SUS (BRASIL, 2013). Os princípios em questão são: Diálogo; Construção compartilhada do conhecimento; Amorosidade; Problematização; Construção do projeto democrático e popular; Convivência não hierarquizada; e Emancipação. A análise da orientação didático-pedagógica do curso, a partir do estudo da matriz curricular, da metodologia e dos materiais didáticos, visa a identificar se os princípios previstos na PNEP-SUS estão contemplados na abordagem pedagógica do curso, o qual toma como objeto de estudo o Guia do Curso de Aperfeiçoamento em Educação Popular em Saúde (BORNSTEIN et al., 2016).

A Educação Popular (HOLLIDAY, 2006a), cujos princípios ancoram o Guia do Curso de Aperfeiçoamento em Educação Popular em Saúde, tem tido uma importância estratégica para a construção da cidadania e para a garantia do direito à saúde no Brasil, sobretudo ao longo das últimas décadas. De acordo com Bornstein et al. (2016, p. 13), a Educação Popular tem sido, desde a década de 1960, uma “[...] prática contrária às formas de dominação, opressão, discriminação e violência que incidem sobre as pessoas em geral e sobre a classe trabalhadora", inspirada nas bases filosóficas da Pedagogia Crítica e no pensamento de Paulo Freire (FREIRE, 1996; MOTA NETO; STRECK, 2019). Segundo Holliday (2006b), as práticas de Educação Popular são inseridas nos contextos sociais e tem como objetivo buscar soluções para os problemas e as necessidades, de forma a elaborar estratégias político-pedagógicas para intervir na realidade.

Os fundamentos e os princípios da Educação Popular têm influenciado muitas das experiências exitosas da educação em saúde, especialmente no campo da saúde pública. Para Bornstein et al. (2016), esse enfoque educativo no âmbito da saúde preconiza a transformação democrática da realidade e a superação das injustiças sociais. A implementação da PNEP-SUS tem sido o resultado de um processo dialógico com a participação de movimentos sociais e de instâncias governamentais para a garantia do direito à saúde no Brasil. A PNEP-SUS visa a valorizar a formação, a comunicação, a produção de conhecimento e a criação de práticas que oportunizem a formação de trabalhadores e de atores sociais em saúde na perspectiva da Educação Popular.

O aporte teórico-metodológico deste estudo apoia-se nos fundamentos da Educação Popular (HOLLIDAY, 2006a; MEJÍA, 2011) inspirado nas bases filosóficas da Pedagogia Crítica (FREIRE, 2005) ao compreender o processo educativo como meio para uma educação como prática da liberdade. Esse posicionamento teórico-metodológico está alinhado ao pensamento de Paulo Freire $(1992,2005,2008)$ e com a sua contribuição para a construção de uma pedagogia problematizadora, pautada pela pergunta (FREIRE, 1985) e em consonância aos princípios da PNEP-SUS (BRASIL, 2013). Nesse enfoque, a educação é crítica, conscientizadora e dialógica, em que educador e educando sistematizam seus saberes e constroem conhecimento de forma compartilhada, em uma prática reflexiva para o exercício, ou para a prática da liberdade, segundo Freire (2005). Segundo o autor, esse processo de ensino e de aprendizagem envolve o afeto, a amorosidade, mas, sobretudo, o tensionamento e a problematização da realidade para a tomada de consciência pelos sujeitos, com o objetivo, no contexto de formação em Educação Popular em Saúde, de que se apropriem do seu processo de autocuidado e de cuidado do outro de forma autônoma.

Este artigo, portanto, apresenta uma pesquisa qualitativa (SAMPIERI; COLLADO; LUCIO, 2013) que analisa a presença dos princípios da PNEP-SUS nas atividades didáticopedagógicas do Guia do Curso de Formação em Educação Popular em Saúde, promovido pela

Práxis Educativa, Ponta Grossa, v. 16, e2116613, p. 1-19, 2021

Disponível em: <https://www.revistas2.uepg.br/index.php/praxiseducativa > 
Educação Popular e Pedagogia Crítica: os princípios pedagógicos freireanos na formação de Educadores...

Escola Politécnica de Saúde Joaquim Venâncio da Fundação Oswaldo Cruz (EPSJV/FIOCRUZ) em parceria com a Secretaria de Gestão Estratégica e Participativa do Ministério da Saúde (SGEP/MS), com base na metodologia Análise de Conteúdo (BARDIN, 2011) .

A condução deste estudo deu-se por meio da análise das relações entre os princípios da PNEP-SUS e as estratégias de aprendizagem previstas nos eixos temáticos do Curso. Dessa forma, objetivou-se verificar como a sistematização de um processo de ensino e de aprendizagem, baseado nas postulações da Pedagogia Crítica e no planejamento das situações de aprendizagem, descritas no Guia, podem promover a construção do conhecimento de forma autônoma e crítica, de modo a servir de referência para a organização pedagógica de outros processos educativos libertadores. Essa análise visou promover a valorização dos saberes e da cultura local, sobretudo no âmbito do ensino na saúde e na curricularização da extensão universitária popular.

Nesse contexto, os dados desta pesquisa foram produzidos e analisados com base no método Análise de Conteúdo (AC) de acordo com Bardin (2011). O método permitiu realizar a análise dos enunciados presentes nos documentos da PNEP-SUS e do Guia Didático do Curso, a partir das fases que a compõem, de modo que foi possível examinar as especificidades da estratégia pedagógica formativa do curso e a sua articulação aos princípios da Pedagogia Crítica.

O artigo está dividido em sete seções, distribuídas da seguinte forma: Introdução; Os princípios da Educação Popular e a Pedagogia Crítica; A Educação Popular e a Política Nacional de Educação Popular em Saúde (PNEP-SUS); Curso de Aperfeiçoamento em Educação Popular em Saúde; Metodologia; Análise e discussão dos resultados; e Considerações finais. Na próxima seção, discorre-se acerca da Educação Popular e da Pedagogia Crítica.

\section{Os princípios da Educação Popular e a Pedagogia Crítica}

Esta seção dedica-se à apresentação dos fundamentos da Educação Popular, de seus princípios e suas práticas, assim como da sua relação com a Pedagogia Crítica. Cabe destacar que a concepção de Educação Popular (HOLLIDAY, 2006a) surgiu no âmbito dos movimentos sociais organizados, em especial na América Latina, com vistas a romper com as cadeias de opressão, herdadas do colonialismo, os quais visavam ao fomento da autonomia do povo e da construção de uma consciência própria (não apenas política, mas social, ética e cultural) para a promoção de uma práxis social e popular transformadora.

Os fundamentos teóricos da Educação Popular estão pautados na ideia de participação popular nos processos sociais decisórios, a partir de práticas que incentivem a legitimação e a sistematização de saberes dispersos pelo território no qual os educandos se encontram. Isso tem como objetivo agenciar a ação democrática e democratizadora, assim como a organização social e política dos sujeitos, com base no resgate dos seus papéis em sua própria transformação e participação autêntica no processo de construção de saberes, em seu protagonismo individual, social e político.

Brandão (2006) e Mota Neto e Streck (2019) entendem que importantes mobilizações populares em prol da educação ocorreram, em especial, a partir da década de 1960, em direção a um modelo educacional progressista. Nesse contexto, Brandão (2006) destaca a importância da Educação Popular, pois, a partir dela, as classes populares que estavam em vulnerabilidade foram convocadas a assumir o protagonismo social em uma realidade até então extremamente opressora e precarizada no Brasil. A Educação Popular é, portanto, um movimento que tem demonstrado ocupar uma função de resistência e de descolonização da produção do conhecimento, e que

Práxis Educativa, Ponta Grossa, v. 16, e2116613, p. 1-19, 2021

Disponível em: < https://www.revistas2.uepg.br/index.php/praxiseducativa> 
segundo Mota Neto e Streck (2019, p. 221), atua como uma luta "[...] pela superação das relações de colonialidade do saber, do ser e do poder".

De acordo com Paludo (2006), a Educação Popular emergiu em um campo de disputas sociais, resultantes do desenvolvimento sócio-histórico latino-americano, sendo atrelada aos processos socioculturais e políticos daquele cenário. Nessa conjuntura, a autora destaca a importância da obra de Paulo Freire, assim como de outras teorias no campo social, político, educacional e filosófico, a partir de experiências de resistência realizadas no campo da arte e da cultura (PALUDO, 2006).

Historicamente, ocorreram ressignificações no conceito de Educação Popular, as quais foram apropriadas em diferentes domínios e direcionaram as relações e as práticas educativas. No campo educacional, em tensionamento às práticas educativas baseadas no modelo tradicional, tecnicista e hegemônico, as características da Educação Popular, segundo Holliday (2006a), construíram um paradigma educativo na direção a uma Pedagogia Crítica. Esta surgiu a partir do movimento da escola nova, especialmente por meio da contribuição da crítica social dos conteúdos.

Essa concepção progressista visou a organizar os processos educativos, a partir dos saberes advindos da experiência concreta dos sujeitos, de suas demandas, suas necessidades locais e regionais e encontrou ressonância na obra de Paulo Freire. O educador critica o modelo de ensino conteudista, pautado na transmissão de conhecimento e o processo comunicacional unidirecional e hierarquizado, em que os sujeitos são considerados receptores de conteúdos informacionais, tendência intitulada por Freire (2005) como Educação Bancária. Nesse sentido, a Educação Popular configurou-se como um modo de organização do processo de ensino e de aprendizagem capaz de dialogar com a construção de relações sociais horizontais, que tomam o sujeito como um ser histórico e transformador de si mesmo e de sua realidade (MEjÍA, 2011). Com base no movimento da Pedagogia Crítica e em princípios de emancipação social, advindos das práticas de Educação Popular, a construção de conhecimento e a tomada de consciência deixaram de ser privilégios e passaram a ser entendidas como formas de libertação de uma ordem social opressora.

Alinhado a essa concepção, Paulo Freire (1992, 1996, 2005, 2008) propôs refletir a construção de práticas de liberdade, com base no princípio da autonomia, de modo a considerar que, para a emancipação dos sujeitos, o processo educativo deveria ser pautado no diálogo, na amorosidade, na conscientização, na problematização do conhecimento, na constante reflexão $a$ partir da e sobre a realidade, na participação democrática e na emancipação, resultando em uma práxis transformadora.

Cabe destacar que, na perspectiva epistemológica Freireana (FREIRE, 2005), a referência de sua concepção educacional está fundamentada na teoria da ação dialógica. Nela, as ações realizadas constituem-se a partir da ideia de que "[...] os sujeitos se encontram para a transformação do mundo em co-laboração” (FREIRE, 2005, p. 191). O diálogo para Freire compõe-se pelo encontro entre as pessoas, que é mediatizado pelo mundo, e que, ao ser pronunciado de modo colaborativo, acaba por desvelado e transformado (FREIRE, 2005). No que se refere à relação entre educador e educando, o diálogo constitui-se como uma ação, que considera os saberes dos educandos e problematiza a realidade deles (FREIRE; GUIMARÃES, 1982). Por isso, está relacionado não somente à fala, mas, especialmente, à ação de escuta e à capacidade de colocar-se no lugar do outro em comunhão com ele.

O diálogo, como uma prática, relaciona-se à capacidade de amar, que, segundo Freire (2005), configura-se como ato de coragem, de comprometimento com o outro e com a causa de sua libertação. O diálogo amoroso é construído pelas pessoas com base em seus diferentes

Práxis Educativa, Ponta Grossa, v. 16, e2116613, p. 1-19, 2021 Disponível em: <https://www.revistas2.uepg.br/index.php/praxiseducativa > 
Educação Popular e Pedagogia Crítica: os princípios pedagógicos freireanos na formação de Educadores...

contextos, que problematizados, leva-as à conscientização. A partir disso é possível uma construção conjunta em uma dinâmica de ação-reflexão-ação (FREIRE, 2005).

Essa concepção inspira a Educação Popular (HOLLIDAY, 2006a, 2006b), que, no âmbito das ações de educação em saúde, visa a produzir e a ampliar o direito, o cuidado e a promoção da saúde da população. Na próxima seção, apresentar-se-á a organização da PNEP-SUS, a partir dos princípios da Educação Popular.

\section{A Educação Popular e a Política Nacional de Educação Popular em Saúde}

As práticas de educação em saúde estiveram atreladas à relação entre conhecimento e comportamento, marcados desde o início do século XX pela perspectiva da transição epidemiológica em saúde e pela mudança de cenário de demanda de erradicação das doenças infectocontagiosas e do controle das epidemias e pandemias como causa de adoecimento e morte (DOWIE; TANNAHIL; TANNAHIL, 1996; LAURENTI, 1990). Até meados da década de 1980, houve a prevalência do modelo de saúde sanitária (CAMPOS, 1988) no país, o qual operou as práticas e o modelo de atenção à saúde e sofreu uma ruptura com o advento do SUS na década de 1980, que instituiu um novo paradigma. Cyrino (2009) refere que, nesse período, houve a transição do paradigma da saúde centrado na doença, de modo a deslocar o então modelo de educação sanitária vigente em direção à emergência de um novo modelo de cuidado e de atenção, marcada pelo paradigma da prevenção, da promoção da saúde e da educação em saúde.

Nesse cenário, o Brasil consolidou, na década de 1980, uma política que garante o acesso universal à saúde pela população brasileira, sendo uma conquista definida pelo art. 198 da Constituição Federal de 1988, na qual a saúde passa a ser descrita como "direito de todos e dever do Estado" (BRASIL, 1988, p. 133), instituindo, assim, o Sistema Único de Saúde - SUS. Além de garantir a universalidade de acesso ao sistema, o SUS apresenta como princípios: (i) a integralidade, (ii) a equidade e (iii) a participação popular. No que tange ao princípio da participação, Cyrino (2009) declara que a Educação Popular tem papel fundamental para fomentar o exercício e a consolidação de uma saúde, baseada na cidadania crítica e transformadora. Dessa forma, a Educação Popular em Saúde está pautada na valorização dos saberes populares e da multiplicidade de expressões culturais locais dispersas no território, de forma a incentivar a participação e as ações coletivas no contexto da promoção da saúde no Brasil.

Segundo Gomes e Merhy (2011), o processo de construção e de consolidação da PNEPSUS teve início em um campo de disputas pelo direito à saúde na década de 1990, marcado pela luta em prol da implantação e da expansão do SUS, com a realização de conferências de saúde nas esferas municipal, estadual e nacional. No ano de 1998, houve a criação da Rede Nacional de Educação Popular em Saúde no Brasil, de modo a garantir o início da participação popular e o debate sobre os determinantes sociais em saúde no âmbito do SUS. A pauta popular no SUS ganhou fortalecimento em 2000 com a criação do primeiro Grupo Temático de Educação Popular na Associação Brasileira de Saúde Coletiva (ABRASCO), com vistas a discutir sobre a demanda pela participação social para a construção e o fortalecimento da perspectiva democrática do SUS. No ano de 2003, fruto da luta de movimentos sociais, a Articulação Nacional de Movimentos e Práticas de Educação Popular em Saúde (ANEPS) passou a ser reconhecida no âmbito do SUS e a ocupar-se em discutir os processos educativos em saúde com base na consciência crítica e na cidadania participativa.

Os debates da ANEPS são inspirados pela metodologia freireana (FREIRE, 1992, 1996, 2005, 2008) para a efetivação de ações de educação em saúde. Em direção ao movimento de consolidação da perspectiva popular em saúde, em 2009, criou-se o Comitê Nacional de Educação

Práxis Educativa, Ponta Grossa, v. 16, e2116613, p. 1-19, 2021

Disponível em: < https://www.revistas2.uepg.br/index.php/praxiseducativa> 
Popular em Saúde (CNEPS) junto à Secretaria de Gestão Participativa do Ministério da Saúde para a formulação da proposta de texto da PNEP-SUS. No ano de 2013, a PNEP-SUS foi aprovada pelo Conselho Nacional de Saúde (CNS), a qual foi o resultado de um processo dialógico longo que contou com a participação de movimentos sociais e instâncias governamentais, por meio do CNEPS. Além do fomento à cidadania e ao direito à saúde por meio da participação popular, a PNEP-SUS visa a valorizar a formação, a comunicação e a produção de conhecimento dos trabalhadores e dos atores sociais em saúde na perspectiva da Educação Popular. A seguir, serão descritos os princípios teórico-metodológicos da Pedagogia Crítica freireana presentes na PNEPSUS.

\section{Os princípios da Política Nacional de Educação Popular em Saúde}

As bases teórico-metodológicas descritas na PNEP-SUS estão organizadas em sete princípios norteadores, a saber: (1) Diálogo; (2) Construção compartilhada do conhecimento; (3) Amorosidade; (4) Problematização; (5) Construção do projeto democrático e popular; (6) Convivência não hierarquizada; e (7) Emancipação. Esses princípios presentes na fundamentação legal da PNEP-SUS tomam por base aspectos teórico-metodológicos inspirados na Pedagogia Crítica freireana (FREIRE, 2005), conforme apresentado a seguir.

(1) Diálogo: segundo Freire (2005), o diálogo é um encontro entre as pessoas, mediatizadas pelo mundo para pronunciá-lo em um movimento no qual a existência humana é problematizada e significada. Ao ser fundamental também para as práticas educativas, viabiliza a construção coletiva e compartilhada de conhecimento. Pressupõe, na PNEP-SUS, o conhecimento como produção histórico-social dos sujeitos construído a partir do diálogo. Assim, o diálogo prevê o amor ao mundo e às pessoas, prevê a crença na natureza de ser mais do ser humano, a esperança e o reconhecimento das diferenças sem negá-las, mas, sim, de modo a promover sua compreensão.

(2) Construção compartilhada do conbecimento: de acordo com Freire (2005), ocorre nas relações que se estabelecem entre as pessoas e destas com o mundo, a partir da imersão na realidade. No contexto da PNEP-SUS, visa a compreender e a transformar as ações de saúde, desde suas dimensões epistemológicas, teóricas, políticas e aplicadas, cujo ponto de partida são o conhecimento e as exigências normativas, os quais são produzidos e acumulados pela vivência subjetiva de cada um.

(3) Amorosidade: Freire (2005) explica que a educação é um ato de amor, e este é um ato de coragem que se dá no comprometimento com a causa dos oprimidos, com vistas à sua libertação. No contexto das práticas em saúde, a amorosidade deve estar presente no vínculo afetivo da relação educativa. A amorosidade permite que o afeto se torne elemento estruturante da busca pela saúde, o qual atua de forma intrínseca no processo de humanização do SUS, ao reconhecer o outro em sua totalidade e em sua diversidade. Educar em saúde com amorosidade significa proporcionar situações de ensino e de aprendizagem, a partir das quais os educandos se tornam autônomos e verdadeiros construtores de seu próprio conhecimento.

(4) Problematização da realidade: é a avaliação e o questionamento da realidade a partir de suas causas e de seus efeitos, bem como a análise de suas estruturas culturais e sociais opressoras, a fim de compreendê-las e transformá-las. Para Freire (2005), a conscientização é parte do processo histórico, o qual implica o engajamento dos homens ao assumir papel de sujeitos protagonistas. Como princípio previsto na PNEP-SUS, a problematização propõe a construção de práticas em saúde alicerçadas na leitura e na análise crítica da realidade, de maneira que os sujeitos busquem novas formas de (re)construir a(s) realidade(s), com vistas à humanização e à libertação.

Práxis Educativa, Ponta Grossa, v. 16, e2116613, p. 1-19, 2021

Disponível em: < https://www.revistas2.uepg.br/index.php/praxiseducativa > 
Educação Popular e Pedagogia Crítica: os princípios pedagógicos freireanos na formação de Educadores...

(5) Construção de um projeto democrático e popular: essa construção ocorre a partir das buscas dos sujeitos pela transformação de suas realidades, tendo em vista as relações com as pessoas e com o mundo, cujos pressupostos são a conscientização e a autonomia dos sujeitos. O princípio norteador da PNEP-SUS para a construção do projeto democrático e popular visa a produzir ações educativas, voltadas ao fortalecimento do sentido de coletividade, na perspectiva de um modelo social justo e democrático, com o protagonismo social para a superação das desigualdades socioeconômicas e para a sua relação com os processos de saúde e de adoecimento.

(6) Convivência não bierarquizada: de acordo com Freire (2005), caracteriza-se como o pensamento horizontal, no qual não há saber mais, nem saber menos, mas, sim, saberes diferentes; além disso, indica que a educação deve levar em conta a democracia e a horizontalidade nas relações. Esse princípio pode ser mobilizado por meio de práticas de debate, de reflexão e de tomada de decisão conjunta. No âmbito das práticas de saúde, para o exercício da cidadania, operase para a consolidação de transformações das situações de saúde da população, por meio da construção de conhecimento de forma compartilhada. Isso implica a construção de espaços de produção de saúde que considerem a inserção dos diferentes atores envolvidos e legitimem os saberes, sejam estes provenientes da ancestralidade, da experiência vivida ou da técnica-científica.

(7) Emancipação: a emancipação resulta da busca por novas possibilidades para a organização popular, de modo a romper com a exclusão social e as formas de opressão, ao mesmo tempo que estimula a intervenção no mundo em todas as situações que perpassam o cotidiano, de modo a trabalhar em prol da construção de uma sociedade democrática. No âmbito da Educação em Saúde, a emancipação visa a favorecer a atuação dos trabalhadores, das lideranças sociais e da população em geral, nos processos de conquistas do direito à saúde e ao fortalecimento da participação social. Os princípios descritos na PNEP-SUS, fundamentados na Pedagogia Crítica freireana (FREIRE, 2005), organizam as atividades propostas no projeto político do Curso de Aperfeiçoamento em Educação Popular em Saúde. Na próxima seção, serão apresentadas as características gerais e a estrutura pedagógica descritas no Guia do Curso de Aperfeiçoamento em Educação Popular em Saúde.

\section{O Curso de Aperfeiçoamento em Educação Popular em Saúde}

O Curso de Aperfeiçoamento em Educação Popular em Saúde atuou como uma das estratégias prioritárias do plano operativo da PNEP-SUS, o qual serviu de instrumento de apoio à sua implantação. O planejamento pedagógico do curso contou com as equipes do Departamento de Apoio à Gestão Participativa/Secretaria de Gestão Estratégica e Participativa do Ministério da Saúde (DAGEP/SGEP) e da Escola Politécnica de Saúde Joaquim Venâncio da Fundação Oswaldo Cruz (EPSJV/FIOCRUZ).

A primeira edição do Curso de Formação de Educadores Populares em Saúde, o EdPopSUS 1 ocorreu entre os anos de 2013 e 2014, com uma carga horária de 53 horas, ofertado em nove Unidades Federativas, a saber: Bahia, Ceará, Distrito Federal, Piauí, Pernambuco, Rio de Janeiro, Rio Grande do Sul, São Paulo e Sergipe. Durante o ano de 2015, foi desenvolvido um novo planejamento para o lançamento da $2^{a}$ edição do curso, realizado no início de 2017 . O EdPopSUS 2 foi planejado e ofertado na modalidade presencial, com duração de 160 horas, o qual previu a formação de turmas distribuídas em 15 estados brasileiros, a saber: Amazonas, Bahia, Ceará, Maranhão, Mato Grosso, Minas Gerais, Pará, Paraíba, Pernambuco, Piauí, Rio de Janeiro, Rio Grande do Sul, Roraima, São Paulo e Sergipe. A carga horária do curso foi organizada em 136 horas presenciais e 24 horas de Trabalho de campo, distribuídas em encontros semanais de oito horas, em aproximadamente 17 encontros, conforme apresentado no Guia do Curso de Aperfeiçoamento em Educação Popular em Saúde elaborado para a 2a edição (EdPopSUS 2).

Práxis Educativa, Ponta Grossa, v. 16, e2116613, p. 1-19, 2021

Disponível em: <https://www.revistas2.uepg.br/index.php/praxiseducativa> 
A abordagem metodológica disposta no Projeto Político Pedagógico do EdPopSUS 2 foi elaborada a partir da concepção de uma metodologia crítica e participativa (FREIRE, 2005; VENTOSA, 2016), a qual contou com o desenvolvimento de estratégias de promoção de vivências e de reflexões sobre as experiências dos sujeitos, o diálogo com os saberes já sistematizados e a relação entre os seus saberes e a construção de novos conhecimentos. As atividades previstas no curso versaram sobre a problematização de temas, como a determinação social do processo saúdedoença e a demanda pela promoção de práticas humanizadas e de cuidados integrais, fortalecidas pelos saberes populares.

O conteúdo programático do curso foi desenvolvido tendo em vista a atuação dos profissionais da Atenção Básica do SUS e o seu envolvimento com o território e os processos de saúde e de cuidado da população, experienciados em sua prática profissional cotidiana. Desse modo, a matriz curricular do curso (EdPopSUS 2) foi delineada a partir de seis grandes eixos temáticos, os quais abrangem temas e conteúdos da práxis dos profissionais. A seguir, na Tabela 1 , é apresentada a estrutura curricular e a distribuição da carga horária do curso.

Tabela 1 - Estrutura curricular do EdPopSUS 2

\begin{tabular}{l|c|c|c}
\hline Eixos Temáticos & Presencial & Trabalho de campo & Total \\
\hline $\begin{array}{l}\text { Eixo I: A construção da gestão participativa como fio } \\
\text { condutor do processo educativo. }\end{array}$ & $16 \mathrm{~h}$ & $4 \mathrm{~h}$ & $\mathbf{2 0 h}$ \\
\hline $\begin{array}{l}\text { Eixo II: A Educação Popular no processo de trabalho em } \\
\text { saúde. }\end{array}$ & $16 \mathrm{~h}$ & $4 \mathrm{~h}$ & $\mathbf{2 0 h}$ \\
\hline Eixo III: O direito à saúde e à promoção da equidade. & $24 \mathrm{~h}$ & $4 \mathrm{~h}$ & $\mathbf{2 8 h}$ \\
\hline Eixo IV: Território, lugar de história e memória. & $16 \mathrm{~h}$ & $4 \mathrm{~h}$ & $\mathbf{2 0 h}$ \\
\hline $\begin{array}{l}\text { Eixo V: Participação social e participação popular no } \\
\text { processo de democratização do Estado. }\end{array}$ & $24 \mathrm{~h}$ & $4 \mathrm{~h}$ & $\mathbf{2 8 h}$ \\
\hline $\begin{array}{l}\text { Eixo VI: O território, o processo saúde-doença e as práticas } \\
\text { de cuidado. }\end{array}$ & $32 \mathrm{~h}$ & $4 \mathrm{~h}$ & $\mathbf{3 6 h}$ \\
\hline Encerramento. & $8 \mathrm{~h}$ & & $\mathbf{8 h}$ \\
\hline Carga horária total do curso. & $136 \mathrm{~h}$ & $24 \mathrm{~h}$ & $\mathbf{1 6 0 h}$ \\
\hline
\end{tabular}

Fonte: Elaborada pelos autores com base no Guia do Curso de Aperfeiçoamento em Educação Popular em Saúde (EdPopSUS 2).

Os materiais e os recursos didáticos do curso foram elaborados com base em princípios teórico-metodológicos para a formação crítica e disponibilizados aos educadores e aos educandos participantes do EdPopSUS 2, de forma a contribuir e a guiar o processo de ensino e de aprendizagem. Esses recursos foram compostos por um conjunto de cadernos (Guia do curso e livro de textos de apoio) distribuídos para a condução do trabalho pedagógico, o qual contava com conteúdos básicos para o desenvolvimento do curso, com vistas à problematização das práticas e da reflexão sobre a realidade. O Guia do Curso foi produzido em duas versões pelo Programa de Qualificação em Educação Popular em Saúde: a) versão digital ${ }^{3}$ e b) versão impressa ${ }^{4}$.

O curso EdPopSUS 2 foi organizado em seis eixos temáticos, divididos em atividades presenciais e Trabalhos de campo, o qual perfez a carga horária total de 160 horas. O objetivo do Guia do curso foi possibilitar um caminho comum na trajetória formativa dos educandos, de forma a respeitar as características regionais de cada uma das turmas (cultura local, demandas de saúde, etc.). $\mathrm{Na}$ etapa de planejamento do curso, o Guia foi elaborado a partir do debate promovido em

\footnotetext{
${ }^{3}$ Disponível em: http://www.edpopsus.epsjv.fiocruz.br/. Acesso em: 7 ago. 2020.

${ }^{4}$ Catalogada na Biblioteca Emília Bustamante da Escola Politécnica de Saúde Joaquim Venâncio (EPSJV) da Fiocruz. Relativo à ficha técnica do Guia, a versão digital poderá ser consultada como Guia do Curso de Aperfeiçoamento em Educação Popular em Saúde, com a organização de Vera Joana Bornstein et al., publicado no Rio de Janeiro, EPSJV, em 2016. 70 páginas.
}

Práxis Educativa, Ponta Grossa, v. 16, e2116613, p. 1-19, 2021 Disponível em: <https://www.revistas2.uepg.br/index.php/praxiseducativa > 
oficinas que contaram com a presença de lideranças dos coletivos de Educação Popular em Saúde, de representantes de escolas técnicas do SUS, de movimentos sociais e de participantes da primeira edição do Curso (BORNSTEIN et al., 2016). Os eixos temáticos organizavam os objetivos específicos, estes desdobrados em atividades distribuídas ao longo dos 17 encontros do curso. Cada encontro possuía cerca de duas a três atividades, seguidas ou não de um Trabalho de campo, conforme apresentado na Quadro 1. A partir do Guia do Curso de Aperfeiçoamento em Educação Popular em Saúde, apresenta-se o Quadro 1 com a Sequência Didática do Curso, de modo a ilustrar a composição dos eixos, de seus objetivos gerais e das atividades previstas para cada encontro.

Quadro 1 - Sequência didática do EdPopSUS 2

\begin{tabular}{|c|c|c|}
\hline \multicolumn{3}{|c|}{ Sequência didática do curso } \\
\hline Eixos temáticos & Objetivos gerais & Encontro e atividades previstas \\
\hline \multirow[t]{2}{*}{$\begin{array}{l}\text { Eixo 1 - construção } \\
\text { da } \\
\text { participativa gestão } \\
\text { processo educativo. }\end{array}$} & \multirow[t]{2}{*}{$\begin{array}{l}\text { Apresentar a gestão do } \\
\text { curso. }\end{array}$} & $\begin{array}{l}\text { Encontro 1: (1) apresentação dos educandos; (2) escrita de uma } \\
\text { carta de expectativas; (3) construção de pactos de organização da } \\
\text { turma; (4) Trabalho de campo } 1 \text { (realização): sistematização das } \\
\text { experiências dos educandos por meio de um diálogo sobre as suas } \\
\text { realidades. }\end{array}$ \\
\hline & & $\begin{array}{l}\text { Encontro 2: (1) Trabalho de campo } 1 \text { (apresentação em grupos); } \\
\text { (2) plenária, com sistematização de experiências; (3) reflexão sobre } \\
\text { classes trabalhadoras da saúde (debate com base na leitura de três } \\
\text { textos sobre atuação de agentes comunitários, de agentes de } \\
\text { vigilância e de trabalhadores sociais em saúde); (4) Trabalho de } \\
\text { campo } 2 \text { (realização): experiências educativas dos educandos } \\
\text { (atividade individual). }\end{array}$ \\
\hline \multirow[t]{2}{*}{$\begin{array}{l}\text { Eixo } 2 \text { - educação } \\
\text { popular no processo } \\
\text { de trabalho em } \\
\text { saúde. }\end{array}$} & \multirow[t]{2}{*}{$\begin{array}{l}\text { Promover a reflexão } \\
\text { sobre a importância da } \\
\text { educação popular no } \\
\text { processo de trabalho } \\
\text { em saúde. }\end{array}$} & $\begin{array}{l}\text { Encontro 3: (1) Trabalho de campo } 2 \text { (apresentação): aspectos } \\
\text { positivos e negativos de cada prática; (2) debate sobre a Educação } \\
\text { Popular em Saúde como possibilidade teórico-metodológica no } \\
\text { processo de trabalho em saúde (roda de conversa, vídeo e leitura } \\
\text { de textos de apoio); (3) Trabalho de campo } 3 \text { (realização): } \\
\text { atividade educativa sobre Educação Popular, leitura de texto de } \\
\text { apoio sobre círculo de cultura e o planejamento participativo na } \\
\text { Educação Popular em Saúde. }\end{array}$ \\
\hline & & $\begin{array}{l}\text { Encontro 4: (1) Trabalho de campo } 3 \text { (apresentação); (2) leitura } \\
\text { de texto de apoio e debate sobre o trabalho em saúde; (3) Trabalho } \\
\text { de campo } 4 \text { (realização): temática sobre o círculo de cultura como } \\
\text { método participativo, leitura de textos e problematização da } \\
\text { realidade; (4) Educação Popular como prática social e profissional } \\
\text { (círculo de cultura sobre o acesso aos serviços de saúde). }\end{array}$ \\
\hline \multirow[t]{2}{*}{$\begin{array}{l}\text { Eixo } 3 \text { - direito à } \\
\text { saúde e à promoção } \\
\text { da equidade. }\end{array}$} & \multirow[t]{2}{*}{$\begin{array}{l}\text { Promover o debate e a } \\
\text { reflexão sobre o direito } \\
\text { à saúde na perspectiva } \\
\text { da equidade. }\end{array}$} & $\begin{array}{l}\text { Encontro 5: (1) Trabalho de campo } 4 \text { (apresentação): em plenária, } \\
\text { roda de conversa sobre o direito à saúde e à promoção da equidade } \\
\text { no SUS e dramatização ao som da música "Noite dos mascarados" } \\
\text { (1966), do compositor Chico Buarque de Hollanda; (2) Trabalho } \\
\text { de campo } 5 \text { (realização): sobre a promoção da equidade em saúde } \\
\text { em seu cotidiano e a produção de um pequeno texto. }\end{array}$ \\
\hline & & $\begin{array}{l}\text { Encontro 6: (1) Trabalho de campo } 5 \text { (apresentação): textos } \\
\text { produzidos e painel para posterior debate em plenária; (2) roda de } \\
\text { conversa sobre a dimensão cultural na Educação Popular em } \\
\text { Saúde, leitura de texto; (3) Trabalho de campo } 6 \text { (realização): } \\
\text { registro por meio de fotografias, vídeos, gravações, etc., sobre as } \\
\text { diferentes expressões culturais cotidianas. }\end{array}$ \\
\hline
\end{tabular}

Práxis Educativa, Ponta Grossa, v. 16, e2116613, p. 1-19, 2021 
Fúlvia da Silva Spohr, Mariana Parise Brandalise Dalsotto e Ygor Correa

\begin{tabular}{|c|c|c|}
\hline \multicolumn{3}{|c|}{ Sequência didática do curso } \\
\hline \multirow[t]{2}{*}{ Eixos temáticos } & Objetivos gerais & Encontro e atividades previstas \\
\hline & & $\begin{array}{l}\text { Encontro 7: (1) Trabalho de campo } 6 \text { (apresentação): relações de } \\
\text { expressões culturais com o trabalho em saúde (planejamento e } \\
\text { desenvolvimento), por meio de um debate; (2) avaliação parcial, } \\
\text { construída coletivamente, sistematizada e enviada para a } \\
\text { coordenação estadual. }\end{array}$ \\
\hline \multirow[t]{2}{*}{$\begin{array}{l}\text { Eixo } 4 \text { - território, } \\
\text { lugar de história e } \\
\text { memória. }\end{array}$} & \multirow[t]{2}{*}{$\begin{array}{l}\text { Compreender o } \\
\text { território como um } \\
\text { lugar de história e } \\
\text { memória e reconhecer } \\
\text { o outro como sujeito de } \\
\text { saberes. }\end{array}$} & $\begin{array}{l}\text { Encontro 8: (1) reflexão sobre a dimensão histórica da cultura, } \\
\text { leitura de texto sobre história e memória coletiva e um outro sobre } \\
\text { território - reflexão, em grupos, sobre as temáticas dos textos; }(2) \\
\text { apresentação e problematização do filme "Narradores de Javé"; } \\
\text { (3) Trabalho de campo } 7 \text { (realização): memória e território - } \\
\text { registro em texto, áudio ou vídeo. }\end{array}$ \\
\hline & & $\begin{array}{l}\text { Encontro 9: (1) Trabalho de campo } 7 \text { (apresentação): exposição } \\
\text { dos registros e reflexão sobre a relação entre território e memória } \\
\text { - exibição de vídeo e debate; (2) Trabalho de campo } 8 \text { (realização): } \\
\text { lutas populares no território a partir do registro de movimentos } \\
\text { sociais e acontecimentos políticos, reflexões e escritas sobre como } \\
\text { a Educação Popular pode potencializar as lutas políticas em defesa } \\
\text { da cidadania. }\end{array}$ \\
\hline \multirow[t]{3}{*}{$\begin{array}{l}\text { Eixo } \\
\text { participação social e } \\
\text { popular no processo } \\
\text { de democratização } \\
\text { do estado. }\end{array}$} & \multirow[t]{3}{*}{$\begin{array}{l}\text { Debater sobre os } \\
\text { conceitos } \\
\text { participação social e } \\
\text { participação popular e } \\
\text { sua relação com a } \\
\text { democratização do } \\
\text { Estado brasileiro. }\end{array}$} & $\begin{array}{l}\text { Encontro 10: (1) partilha de situações de opressão por meio de } \\
\text { técnicas do Teatro do Oprimido; (2) Trabalho de campo } 8 \\
\text { (apresentação): colagem dos materiais levados ao curso; (3) leitura } \\
\text { de um texto de apoio sobre participação popular e social; (3) } \\
\text { Trabalho de campo } 9 \text { (realização): sobre o poder de } \\
\text { convencimento dos meios de comunicação, envolvendo a análise } \\
\text { de reportagens, com vistas à construção de um olhar crítico. }\end{array}$ \\
\hline & & $\begin{array}{l}\text { Encontro 11: (1) Trabalho de campo } 9 \text { (apresentação): roda de } \\
\text { conversa; (2) atividade para promover formas de comunicação a } \\
\text { partir dos princípios da Educação Popular (uma dramatização, um } \\
\text { programa de rádio, um mural comunitário, um cartaz, um jornal } \\
\text { local, ou uma matéria para ser divulgada em meios virtuais), com } \\
\text { o intuito de desenvolver uma estratégia ou um material educativo } \\
\text { a partir de problemas de saúde do território. }\end{array}$ \\
\hline & & $\begin{array}{l}\text { Encontro 12: (1) exibição de um documentário intitulado "Utopia } \\
\text { e barbárie"; (2) debate para identificar situações de opressão e de } \\
\text { participação apresentados; (3) segundo debate a partir do texto de } \\
\text { apoio "A luta popular em defesa do SUS"; (4) construção de } \\
\text { esquetes, de um manifesto, de um "júri popular", ou outras } \\
\text { propostas, para problematizar os possíveis interesses na disputa } \\
\text { da saúde; (5) Trabalho de campo } 10 \text { (realização): identificar os } \\
\text { problemas de saúde nos territórios, que podem ser apresentados } \\
\text { a partir de recursos visuais. }\end{array}$ \\
\hline $\begin{array}{l}\text { Eixo } 6 \text { - território, } \\
\text { processo saúde- } \\
\text { doença e práticas de } \\
\text { cuidado. }\end{array}$ & $\begin{array}{l}\text { Compreender a } \\
\text { contribuição político- } \\
\text { metodológica que a } \\
\text { educação popular em } \\
\text { saúde apresenta. }\end{array}$ & $\begin{array}{l}\text { Encontro 13: (1) Trabalho de campo } 10 \text { (apresentação); (2) } \\
\text { sistematização das reflexões por meio da construção de um mapa } \\
\text { ou da elaboração de desenhos; (3) leitura de textos de apoio; (4) } \\
\text { exibição de um pequeno trecho de uma entrevista com Paulo } \\
\text { Freire (1997), com reflexão sobre a relação entre adaptação e } \\
\text { inserção cultural; (5) exibição do vídeo "Pobreza no Brasil: } \\
\text { caminhos da reportagem" (2011); (6) reflexão sobre os vídeos em } \\
\text { grupos e apresentação em plenária. }\end{array}$ \\
\hline
\end{tabular}

Práxis Educativa, Ponta Grossa, v. 16, e2116613, p. 1-19, 2021 Disponível em: < https://www.revistas2.uepg.br/index.php/praxiseducativa> 
Educação Popular e Pedagogia Crítica: os princípios pedagógicos freireanos na formação de Educadores...

\begin{tabular}{|c|c|c|}
\hline \multicolumn{3}{|c|}{ Sequência didática do curso } \\
\hline Eixos temáticos & Objetivos gerais & Encontro e atividades previstas \\
\hline & & $\begin{array}{l}\text { Encontro 14: (1) dramatização de situações de cuidado; (2) leitura } \\
\text { de textos de apoio (3) apresentação do vídeo "Dona Chica: } \\
\text { saberes e fazeres" (2015); (4) Trabalho de campo } 11 \text { (realização): } \\
\text { com o tema do cuidado no território. }\end{array}$ \\
\hline & & $\begin{array}{l}\text { Encontro 15: (1) Trabalho de campo } 11 \text { (apresentação); (2) } \\
\text { realização de oficina de cuidados; (3) Trabalho de campo } 12 \\
\text { (realização): retomada da carta escrita no início do curso e } \\
\text { elaboração de uma nova carta, para relatar as experiências vividas } \\
\text { no curso. }\end{array}$ \\
\hline & & $\begin{array}{l}\text { Encontro 16: (1) Trabalho de campo } 12 \text { (apresentação) } \\
\text { relacionada às cartas escritas no início do curso; (2) avaliação } \\
\text { coletiva do curso; (3) preparação de mostra de experiências do } \\
\text { curso, a partir dos trabalhos realizados pelos educandos no } \\
\text { decorrer do curso. }\end{array}$ \\
\hline & & Encontro 17: Encerramento com a mostra de experiências. \\
\hline
\end{tabular}

Fonte: Elaborado pelos autores.

Esta seção teve a intenção de apresentar a sequência didática, os objetivos gerais e as atividades de ensino propostas no Guia do Curso de Aperfeiçoamento em Educação Popular em Saúde. A sequência didática já permite conhecer os aspectos de seu planejamento por intermédio das situações de aprendizagem descritas, as quais corroboram para a organização pedagógica do curso desenvolvida a partir do referencial da Educação Popular em Saúde, cuja base são os princípios político-pedagógicos da educação popular e da pedagogia crítica. As relações estabelecidas entre as atividades pedagógicas propostas no Guia do Curso de Aperfeiçoamento em Educação Popular em Saúde e os princípios da educação popular e da pedagogia crítica serão desenvolvidas mais adiante. A seguir, apresenta-se a metodologia utilizada para a realização das etapas do estudo.

\section{Metodologia do estudo}

Esta é uma pesquisa qualitativa (SAMPIERI; COLLADO; LUCIO, 2013), apoiada no método de Análise de Conteúdo (BARDIN, 2011). Nesse horizonte, analisou-se a organização pedagógica de um Curso de Formação de Educadores Populares em Saúde, no âmbito do SUS no Brasil, direcionado à formação e ao aperfeiçoamento profissional de equipes de Atenção Básica em Saúde, sob a égide da Pedagogia Crítica (FREIRE, 2005). O referido curso foi uma iniciativa do Ministério da Saúde e da Escola Politécnica em Saúde Joaquim Venâncio, da Fundação Oswaldo Cruz para a implementação da PNEP-SUS (BRASIL, 2013). No que concerne à adoção da Análise de Conteúdo (AC), optou-se pela utilização dessa metodologia para a organização e a produção da análise da pesquisa, uma vez que a $\mathrm{AC}$ é composta por um conjunto de técnicas e de procedimentos sistemáticos, voltados à descrição dos conteúdos das trocas comunicativas (BARDIN, 2011).

Este estudo, ancorado nas postulações de Bardin (2011), contempla três fases, a saber: (a) pré-análise, (b) exploração do material e (c) tratamento dos resultados. $\mathrm{Na}$ fase (a), pré-análise, temse por objetivo a organização do material, por meio da (i) leitura "flutuante" - momento em que se tem o primeiro contato com os documentos em sua totalidade; seguida da (ii) escolha dos documentos (corpus); (iii) formulação de hipóteses e objetivos, a partir da leitura inicial dos dados;

Práxis Educativa, Ponta Grossa, v. 16, e2116613, p. 1-19, 2021 Disponível em: <https://www.revistas2.uepg.br/index.php/praxiseducativa> 
e (iv) elaboração de indicadores para preparação do material para interpretação. Trata-se de um contato inicial com os documentos, como objetos de análise, que, a posteriori, serão submetidos às demais etapas.

Quanto à fase (b) exploração do material, segundo Bardin (2011), envolve assumir tomadas de decisões que sistematizem a exploração do conteúdo em análise, seja de modo manual ou com o auxílio de sistemas computadorizados relativos à organização de dados de pesquisa (unidades de registro), com vistas à sua codificação para posterior classificação e categorização (simbólica ou temática). A categorização possibilita que os códigos sejam agrupados, segregados ou reagrupados, de modo a compor um determinado significado. Segundo as postulações presentes na AC (BARDIN, 2011), uma boa categorização apresenta qualidades como: exclusão, homogeneidade, pertinência, objetividade, fidelidade e produtividade dos dados.

Já a fase (c), tratamento dos resultados, abrange o momento em que se captam os conteúdos manifestos e latentes presentes no material sob análise, para fins de tratamento - quando os resultados pouco lapidados são tratados de maneira a considerá-los significativos e válidos para a AC. Diante do exposto, a seguir, apresenta-se o modo como a AC foi organizada, a saber: na fase (a), pré-análise, realizou-se a (i) leitura "flutuante" dos documentos do marco legal disposto na Portaria N 2.761 de 19 de novembro de 2013, que institui a PNEP-SUS (BRASIL, 2013), no âmbito do SUS; na (ii) escolha dos documentos (corpus), selecionaram-se documentos da PNEPSUS e do Guia Didático do Curso de Aperfeiçoamento em Educação Popular em Saúde (EdPopSUS2); posteriormente, na (iii) formulação de hipóteses e de objetivos, a partir da leitura inicial dos conteúdos dos documentos aqui citados; e (iv) elaboração de indicadores para preparação dos enunciados identificados nos documentos, acerca das especificidades da estratégia pedagógica formativa do curso e sua articulação aos princípios da Pedagogia Crítica (FREIRE, 2005) presentes na PNEP-SUS - (1) Diálogo; (2) Construção compartilhada do conhecimento; (3) Amorosidade; (4) Problematização; (5) Construção do projeto democrático e popular; (6) Convivência não hierarquizada; e (7) Emancipação.

$\mathrm{Na}$ fase (b), exploração do material, foram tomadas decisões quanto à sistematização dos dados e ao modo como ocorreria a exploração do conteúdo em análise, de forma a defini-la, inicialmente, pela identificação de enunciados dos documentos, os quais comporiam unidades de registro, a partir dos princípios da Pedagogia Crítica. Para tanto, analisou-se a orientação didáticopedagógica do curso, a partir do estudo da matriz curricular, em especial quanto às atividades previstas em cada eixo, tendo como finalidade identificar a presença e o modo como são operacionalizados cada um dos sete princípios da PNEP-SUS nas atividades descritas no Guia supracitado. Os enunciados que contêm os princípios foram considerados unidades de registro, com vista à posterior codificação, para fins de classificação e de categorização, por semelhança à definição de cada princípio da Pedagogia Crítica. Posteriormente, realizou-se o agrupamento dos enunciados codificados, de modo a considerar os critérios previstos na AC: exclusão, homogeneidade, pertinência, objetividade, fidelidade e produtividade dos dados.

Já na fase (c), tratamento dos resultados, como etapa em que se conduz a análise de conteúdo, os enunciados voltados aos sete princípios da Pedagogia Crítica foram registrados manualmente e codificados, sem a pretensão de quantificá-los ou apresentá-los, aqui, em excertos, mas, sim, para operacionalizar a relação entre os Princípios da Pedagogia Crítica, os documentos da PNEP-SUS e os documentos do EdPopSUS 2. Desse modo, foi possível compreender (a) a forma de organização da proposta pedagógica do curso em questão, (b) a estrutura curricular do Curso (ver Tabela 1) e (c) a sequência didática do curso, composta por seis eixos temáticos, objetivos de aprendizagem, encontros e atividades previstas (ver Quadro 1). Cabe salientar que o Quadro 1, apresentado anteriormente, elaborado pelos autores deste estudo, como estratégia 
Educação Popular e Pedagogia Crítica: os princípios pedagógicos freireanos na formação de Educadores...

operacional para ilustrar a relação entre os componentes didáticos, permitiu, a posteriori, a condução da análise proposta. Na próxima seção, apresenta-se a discussão das interpretações conduzidas à luz do referencial teórico-metodológico que norteia a presente pesquisa.

\section{Análise e discussão dos resultados}

Nesta seção, apresenta-se a análise das relações tecidas entre os princípios da PNEP-SUS e cada um dos seis eixos temáticos do EdPopSUS 2, sistematizados da seguinte forma: (a) identificação do eixo; (b) carga horária; (c) número de encontros; (d) objetivo do eixo; (e) princípios identificados no eixo; (f) exemplo de pelo menos uma atividade enquadrada em cada eixo.

O Eixo 1, A construção de gestão participativa no processo educativo, com carga horária de 20 horas, distribuídos em dois encontros de 16 horas presenciais e 4 horas de Trabalho de campo, visava a apresentar o curso de modo introdutório aos educandos. Para tanto, identificou-se, por meio da análise da proposta pedagógica e das atividades de ensino e de aprendizagem, a presença dos princípios da PNEP-SUS a saber: (a) o Diálogo aparece presente na atividade de apresentação dos educandos; (b) a Problematização decorre da escrita de carta de expectativas; (c) a Construção do projeto democrático popular foi identificada na proposta de atividade de pactos de organização da turma; e (d) a Convivência não hierarquizada e a Construção compartilhada do conhecimento colocam-se na realização do Trabalho de campo 1.

Os princípios verificados apontam para uma construção pedagógica, a qual tinha por finalidade o compartilhamento de discursos, de saberes e de experiências docentes e discentes, baseada na concepção de protagonismo e de convivência (HOLLIDAY, 2006a), ambas voltadas, no caso deste estudo, ao trabalho em saúde. Inferimos que os princípios verificados têm papel fundamental para o desenvolvimento de competências para a formação da autonomia (FREIRE, 1996) e do protagonismo dos educandos, para a construção da(s) identidade(s) profissional(is) com vistas à promoção da gestão compartilhada nos processos decisórios em saúde e na instrumentalização para a sistematização de experiências em saúde.

A proposição das atividades foi realizada a partir do referencial teórico freireano, compreendido na PNEP-SUS, no qual a construção da gestão participativa é realizada com base nas práticas de liberdade (FREIRE, 2005), pois, a partir da perspectiva freireana, é somente com as pessoas que é possível fazer algo para elas (BRANDÃO, 2006). Desse modo, o processo educativo proposto envolve o incentivo ao protagonismo dos educandos, de forma a compreender o processo formativo como elemento dialético para a mobilização social em relação à universalidade, à equidade e à participação popular em saúde (BRASIL, 2013).

O Eixo 2, A Educação Popular no processo de trabalho em saúde, com carga horária de 20 horas, distribuída em dois encontros de 16 horas presenciais e 4 horas de Trabalho de campo, visava a promover a reflexão sobre a importância da Educação Popular (HOLLIDAY, 2006a; MEJÍA, 2011) no processo de trabalho em saúde. Para tanto, identificou-se, por meio da análise da proposta, a presença dos princípios da PNEP-SUS (BRASIL, 2013), a saber: (a) a Problematização ocorre a partir da atividade de apresentação de Trabalho de campo; (b) a Convivência não hierarquizada e a Construção compartilhada do conhecimento dão-se na atividade de debate e na roda de conversa sobre Educação Popular em Saúde; (c) a Emancipação realiza-se no trabalho de planejamento em grupo na perspectiva da Educação Popular. No planejamento das atividades do Eixo 2, verificou-se a preocupação em construir processos de trabalho em saúde junto aos educandos, pautados em ações didáticas para o planejamento, o desenvolvimento e a avaliação em Educação Popular e Pedagogia Crítica (FREIRE, 1996; MOTA NETO; STRECK, 2019), com o

Práxis Educativa, Ponta Grossa, v. 16, e2116613, p. 1-19, 2021

Disponível em: <https://www.revistas2.uepg.br/index.php/praxiseducativa> 
intuito de construir formas educativas emancipadoras ao problematizar diferentes concepções de educação no campo da saúde.

O Eixo 3, O direito à saúde e à promoção da equidade, com carga horária de 28 horas, distribuída em três encontros de 24 horas presenciais e 4 horas de Trabalho de campo, visava a promover o debate e a reflexão sobre o direito à saúde na perspectiva da equidade. Nesse eixo, constatou-se, durante a análise da proposta pedagógica e das atividades de ensino e de aprendizagem, os seguintes princípios da PNEP-SUS, a saber: (a) o Diálogo faz-se presente na roda de conversa; (b) a Problematização é realizada durante a plenária sobre direito à saúde e à equidade no SUS; (c) a Construção compartilhada do conhecimento dá-se a partir da dramatização ao som da música "Noite dos mascarados", do compositor Chico Buarque de Hollanda; (d) a Convivência não hierarquizada aparece na atividade de registro por meio de fotografias, de vídeos, de gravações, etc., sobre as diferentes expressões culturais cotidianas; (e) a Emancipação e a Amorosidade estão presentes no Trabalho de campo 6 (realização), a partir do registro das fotografias, dos vídeos, das gravações, etc., sobre as diferentes expressões culturais cotidianas; e (g) a Convivência não hierarquizada dá-se na roda de conversa, cujo tema é a dimensão cultural na Educação Popular em Saúde, e na leitura de texto.

A partir da identificação dos princípios que operam no planejamento do Eixo 3, verificouse a participação dos educandos em atividades artísticas e de análise cultural, com o objetivo de discutir elementos do âmbito social, relativos ao tensionamento entre equidades e iniquidades, presentes no território e na relação desses elementos ao direito à saúde no Brasil. A garantia da democratização de elementos da cultura é, na perspectiva freireana (FREIRE, 1992, 1996, 2005), a garantia da manutenção da cultura, de modo a fomentar o acesso ao conhecimento nas diferentes dimensões da vida, especialmente àquelas referentes às múltiplas práticas populares para a promoção e para o direito à saúde, de maneira a garantir a promoção da equidade.

O Eixo 4, Território, lugar de história e memória, com carga horária de 20 horas, distribuída em dois encontros de 16 horas presenciais e 4 horas de Trabalho de campo, visava a compreender o território como um lugar de história e de memória, de forma a reconhecer o outro como sujeito de saberes. A análise do eixo possibilitou apurar, na proposta pedagógica e nas atividades de ensino e de aprendizagem, os seguintes princípios da PNEP-SUS: (a) o Diálogo dá-se no momento de reflexão em grupos sobre a dimensão histórica da cultura, de leitura de um texto sobre história e memória coletiva e um outro sobre território; (b) a Problematização ocorre a partir da apresentação e da discussão sobre o filme "Narradores de Javé"; (c) a Construção compartilhada do conhecimento e a Emancipação aparecem no Trabalho de campo 7, que se realiza a partir do registro em texto, áudio ou vídeo a partir de situações de suas realidades; (d) a Convivência não Hierarquizada, a Amorosidade e a Construção do Projeto Democrático Popular aparecem no Trabalho de campo 8, sobre lutas populares no território, realizado a partir do registro de movimentos sociais e acontecimentos políticos, reflexões e escritas sobre como a Educação Popular pode potencializar as lutas políticas em defesa da cidadania.

Do ponto de vista analítico, em relação ao Eixo 4, observou-se a existência de atividades pautadas em princípios da Educação Popular (HOLLIDAY, 2006a) e da Pedagogia Crítica (MEJÍA, 2011), capazes de discutir a importância do contexto, da história e do diálogo como pontos de partida para a construção de conhecimento de forma crítica (FREIRE, 2005). A importância do resgate da memória e da história em processos educativos participativos, especialmente em Educação Popular, justifica-se pela necessidade de retomar a história para compreender a realidade e, com isso, tomar um lugar de autoria nesse cenário (MOTA NETO; STRECK, 2019). Desse modo, ao promover a reflexão com base na oferta de atividades de expressão cultural, é possível compreender o território como espaço de organização da vida, do trabalho e das lutas populares.

Práxis Educativa, Ponta Grossa, v. 16, e2116613, p. 1-19, 2021

Disponível em: < https://www.revistas2.uepg.br/index.php/praxiseducativa > 
Educação Popular e Pedagogia Crítica: os princípios pedagógicos freireanos na formação de Educadores...

O Eixo 5, Participação social e popular no processo de democratização do Estado, com carga horária de 28 horas, distribuída em três encontros de 24 horas presenciais e 4 horas de Trabalho de campo, visava a debater sobre os conceitos de participação social e de participação popular e sua relação com a democratização do estado brasileiro. Para tanto, identificou-se a presença dos princípios da PNEP-SUS, a saber: (a) a Convivência não hierarquizada se dá na atividade de apresentação do Trabalho de campo 8, na qual os educandos devem partilhar o material pesquisado, por meio da construção de um painel com colagens; (b) a Problematização ocorre a partir da leitura de texto sobre participação popular e social; (c) a Construção compartilhada do conhecimento e a Construção do projeto democrático e popular são empregados na atividade, na qual há a promoção de formas de comunicação a partir dos princípios da Educação Popular (HOLLIDAY, 2006a), por intermédio de uma dramatização, de um programa de rádio, de um mural comunitário, de um cartaz, de um jornal local ou de uma matéria para ser divulgada em meios virtuais, com o intuito de desenvolver uma estratégia ou um material educativo a partir de problemas de saúde do território; e (d) o Diálogo faz-se presente na realização de rodas de conversa.

No planejamento das atividades do Eixo 5, há elementos para a construção de uma crítica à ordem social vigente, de forma a permitir aos educandos compreender os modos de opressão e, com isso, criar possibilidades para a libertação (FREIRE, 2005). Dessa maneira, infere-se que os princípios da PNEP-SUS, baseados no pensamento freireano (FREIRE, 1992, 1996, 2005, 2008) e na Pedagogia Crítica (MEJÍA, 2011), presentes nas atividades descritas no Eixo 5 do Guia do Curso, atuam como didática participativa para uma construção democrática (VENTOSA, 2016), a qual reuniu elementos da cultura popular capazes de produzir um debate sobre os conceitos de participação social e de participação popular e sua relação com a democratização do Estado.

O Eixo 6, O território, o processo saúde-doença e as práticas de cuidado, com carga horária de 36 horas, distribuída em cinco encontros de 32 horas presenciais e 4 horas de Trabalho de campo (incluindo o último encontro do curso, no qual é realizado o encerramento), visava a compreender a contribuição político-metodológica que a Educação Popular em Saúde apresenta. Nesse eixo, identificou-se os princípios de (a) o Diálogo e a Construção compartilhada do conhecimento na atividade de sistematização das reflexões por meio da construção de um mapa conceitual ou da elaboração de desenhos, realizados em grupo; (b) a Problematização, realizada a partir da exibição de um pequeno trecho de uma entrevista com Paulo Freire, com reflexão sobre a relação entre adaptação e inserção cultural; e (c) a Construção compartilhada do conhecimento e a Amorosidade, que se fazem presentes na atividade de dramatização de situações de cuidado e na realização de uma oficina de cuidado em grupo.

Identificou-se, nos dois últimos encontros previstos no planejamento do curso, a integração dos sete princípios da PNEP-SUS (BRASIL, 2013), presentes nas atividades de preparação para a mostra de experiências do curso, a partir da exibição dos trabalhos realizados pelos educandos no decorrer do processo formativo. Isso demonstra que a perspectiva teórico-metodológica da Educação Popular é, em potência, propulsora da politização da relação entre os sujeitos ao propor um movimento de diálogo participante para organizar os conhecimentos populares (neste caso, em saúde), de forma a possibilitar a atribuição de sentido(s) e a significação dos conhecimentos a partir de diferentes contextos e realidades. Assim, a proposta didática prevista para as atividades do Eixo 6 configura-se como uma importante contribuição político-metodológica para a problematização de temas como a determinação social do processo saúde-doença, a demanda pela promoção de práticas de cuidado integrais e humanizadas, fortalecidas pelos saberes populares e, sobretudo, para a construção da autonomia dos educandos.

Práxis Educativa, Ponta Grossa, v. 16, e2116613, p. 1-19, 2021

Disponível em: <https://www.revistas2.uepg.br/index.php/praxiseducativa> 


\section{Considerações finais}

A Educação Popular é uma prática que valoriza os saberes dos educandos, de modo a fomentar a construção de conhecimentos vinculados a seu contexto concreto a partir de convivências não hierarquizadas entre educadores e educandos nos processos de ensino e de aprendizagem. Os princípios teórico-metodológicos da Educação Popular, quando inseridos em diferentes contextos, visam a organizar as práticas sociais de maneira a potencializar a tomada de consciência para a busca por soluções para os problemas e para as demandas locais e globais. Para isso, uma prática de Educação Popular necessita ser desenvolvida com base no planejamento de estratégias político-pedagógicas alinhadas a princípios que promovam o debate, a reflexão e a tomada de decisões conjuntas. Nesse sentido, a Educação Popular coloca-se no campo da saúde com o intuito de potencializar o trabalho educativo, o qual subsidia a construção de processos educativos dialógicos e participativos no âmbito da saúde.

Com isso, a Educação Popular favorece e valoriza a multiplicidade de saberes e de expressões culturais dispersas no território, de modo a incentivar as ações coletivas no contexto da promoção da saúde no Brasil. Observa-se que o referencial da Pedagogia Crítica e da Educação Popular (FREIRE 1992, 1996, 2005, 2008; HOLLIDAY, 2006a, 2006b; VENTOSA, 2016) foi tomado como base na construção da Política Nacional de Educação Popular em Saúde em especial (PNEP-SUS), a qual orientou seus princípios e guiou as ações formativas em educação em saúde.

Em relação ao que foi exposto, neste estudo, verificou-se a orientação didático-pedagógica do Curso de Aperfeiçoamento em Educação Popular em Saúde, com vistas a identificar se os princípios previstos na Política Nacional de Educação Popular em Saúde (PNEP-SUS) haviam sido contemplados na abordagem pedagógica. Nesse tocante, identificou-se a presença de atividades didáticas, com base no princípio do Diálogo, o qual permite impulsionar a participação popular nas práticas de gestão e o controle social em saúde, de forma a promover o diálogo intersetorial no território de atuação dos educandos. Acerca do princípio da Construção compartilhada do conhecimento, este opera como um dispositivo que garante a visibilidade dos saberes populares e a sistematização das ações de educação popular, de forma a atribuir um estatuto de legitimidade e de articulação política, o qual organiza as práticas populares em saúde.

A Amorosidade, por sua vez, tem um caráter ético fundante ao impulsionar e ao regular toda e qualquer relação humana. Quanto ao exercício da Problematização, este assegura que as práticas em saúde estejam alicerçadas na análise crítica da realidade. No que tange à Construção do projeto democrático e popular, infere-se que o princípio em questão possibilita a ação coletiva, advinda da organização e da articulação entre as diferentes culturas e contextos, de modo a viabilizar a transformação social. Por sua vez, a Convivência não hierarquizada produz a horizontalidade nas relações educativas, de maneira a reforçar a concepção de que todos são construtores de conhecimentos e saberes distintos. Quanto ao princípio da Emancipação, esta visa assegurar que sujeitos venham a agir de forma crítica e consciente e, assim, torna efetiva sua participação nos processos de convivência e interação em saúde.

Evidenciou-se que o planejamento pedagógico do curso, contido no Guia, promoveu a manutenção dos princípios preconizados na PNEP-SUS e reuniu elementos derivados dos fundamentos da Educação Popular e da Pedagogia Crítica, pautados na obra de Paulo Freire. Tendo exposto a relação entre o planejamento do Curso (apresentado no Guia), os princípios da PNEP-SUS e os fundamentos da Educação Popular e da Pedagogia Crítica ao longo do artigo, torna-se evidente a atualidade da perspectiva freireana e a importância epistemológica de tomá-la como referencial teórico-metodológico para planejar e para desenvolver práticas educativas emancipatórias, conscientizadoras e participativas. Observa-se que esse curso pode ser uma

Práxis Educativa, Ponta Grossa, v. 16, e2116613, p. 1-19, 2021 Disponível em: < https://www.revistas2.uepg.br/index.php/praxiseducativa > 
Educação Popular e Pedagogia Crítica: os princípios pedagógicos freireanos na formação de Educadores...

amostra que evidencia o alcance e a profundidade da teoria freireana em diferentes áreas do conhecimento, neste caso, a Educação em Saúde.

Diante disso, observa-se que Paulo Freire tem uma contribuição histórica para a formação humana e para a organização de formas de educação libertadoras, reconhecida internacionalmente. Em razão de sua práxis humanizadora e conscientizadora, seu pensamento pode renascer em diferentes contextos que visem à autoria dos sujeitos por meio da apropriação e da transformação da realidade. A práxis freireana pode, assim, enriquecer o trabalho na saúde e fundar a construção do conhecimento em saúde.

Neste texto, apresentou-se uma possibilidade de organização prática de Educação Popular em Saúde, a qual enaltece a contribuição do referencial teórico freireano, pois entende que este apresenta contribuições para a construção de processos educativos em diferentes contextos. Com base nos fundamentos presentes na obra de Paulo Freire, observou-se que estes podem potencializar estratégias de educação em saúde, sustentadas na democratização das relações de prevenção e de promoção da saúde, com vistas à democratização dos saberes e ao fortalecimento do controle social em saúde no Brasil.

\section{Referências}

BARDIN, L. Análise de conteúdo. São Paulo: Edições 70, 2011.

BORNSTEIN, V. J. et al. (org.). Guia do Curso de Aperfeiçoamento em Educação Popular em Saúde. Rio de Janeiro: EPSJV, 2016. Disponível em: https://bit.ly/2NcNEY6. Acesso em: 10 jul. 2020.

BRANDÃO, C. R. Trinta Anos depois: alguns elementos de crítica atual aos projetos de cultura popular dos movimentos de cultura popular dos anos 1960. In: PONTUAL, P.; IRELAND T. (org.). Educação Popular na América Latina: diálogos e perspectivas. Brasília: Ministério da Educação: UNESCO, 2006. p. 255-261.

BRASIL. [Constituição (1988)]. Constituição da República Federativa do Brasil. Brasília, DF: Senado, 1988.

BRASIL. Ministério da Saúde. Secretaria de Gestão Estratégica e Participativa. Comitê Nacional de Educação Popular em Saúde. Política Nacional de Educação Popular em Saúde. Brasília: MS, CNEPS, 2013.

BRASIL. Portaria Nº 2.761 de 19 de novembro de 2013. Institui a Política Nacional de Educação Popular em Saúde no âmbito do Sistema Único de Saúde (PNEPS-SUS). Brasília: Ministério da Saúde, [2013]. Disponível em: https://bit.ly/3rDHoaT. Acesso em: 5 mar. 2021.

CAMPOS, G. W. S. A reforma sanitária necessária. In: BERLINGUER, G.; TEIXEIRA, S. F.; CAMPOS, G. W. S. (org.). Reforma sanitária: Itália e Brasil. São Paulo: Editora Cebes; Hucitec, 1988. p. 179-194.

CYRINO, A. P. Uma cartografia do autocuidado no diabetes. São Paulo: Editora UNESP, 2009.

DOWIE, R. S.; TANNAHIL, C.; TANNAHIL, A. Heasth promotion: modles and values. 2. ed. Oxford: Oxford University Press, 1996. 
FREIRE, P. A importância do ato de ler: em três artigos que se complementam. 23. ed. São Paulo: Autores Associados, 1985.

FREIRE, P. Extensão ou comunicação. 10. ed. Rio de janeiro: Paz e Terra, 1992.

FREIRE, P. Pedagogia da autonomia: saberes necessários à prática educativa. São Paulo: Paz e Terra, 1996.

FREIRE, P. Pedagogia do oprimido. Rio de Janeiro: Paz e Terra, 2005.

FREIRE, P. Conscientização: teoria e prática da libertação: uma introdução ao pensamento de Paulo Freire. 3. ed. São Paulo: Centauro, 2008.

FREIRE, P.; GUIMARÃES, S. Sobre educação: diálogos. 2. ed. Rio de Janeiro: Paz e Terra Ltda, 1982. $2 \mathrm{v}$.

GOMES L. B.; MERHY. E. E. Compreendendo a educação popular em saúde: um estudo na literatura brasileira. Caderno de Saúde Pública, Rio de Janeiro, v. 27, n. 1, p. 7-18, 2011. DOI: https://doi.org/10.1590/S0102-311X2011000100002

HOLLIDAY, O. J. Ressignifiquemos as propostas e práticas de Educação Popular perante os desafios históricos contemporâneos. In: PONTUAL, P; IRELAND, T. (org.). Educação Popular na América Latina: diálogos e perspectivas. Brasilia: Ministério da Educação: UNESCO, 2006a. p. 233-239.

HOLLIDAY, O. J. Para sistematizar experiências. Tradução Maria Viviana V. Resende. 2. ed. Brasília: MMA, 2006b.

LAURENTI, R. Transição demográfica e transição epidemiológica. In: CONGRESSO BRASILEIRO DE EPIDEMIOLOGIA, 1., 1990, Campinas. Anais [...]. Campinas: ABRASCO, 1990. p. 143-165.

MEJÍA, M. R. Educaciones y pedagogías críticas desde el Sur. Panamá: CEAAL, 2011.

MOTA NETO, J. C. da; STRECK, D. Fontes da Educação Popular na América Latina: contribuições para uma genealogia de um pensar pedagógico decolonial. Educar em Revista, Curitiba, v. 35, n. 78, p. 207-223, nov./dez. 2019. DOI: https://doi.org/10.1590/0104-4060.65353

PALUDO, C. Educação Popular: dialogando com redes latino-americanas (2000-2003). In: PONTUAL, P.; IRELAND T. (org.). Educação Popular na América Latina: diálogos e perspectivas. Brasília: Ministério da Educação: UNESCO, 2006. p. 41-61.

SAMPIERI, R. H.; COLLADO, C. F.; LUCIO, M. B. Metodologia de pesquisa. 5. ed. Porto Alegre: Penso, 2013.

VENTOSA, V. J. Didática da participação: teoria, metodologia e prática. São Paulo. Edições SESC São Paulo, 2016.

Recebido em 10/08/2020

Versão corrigida recebida em 28/02/2021

Aceito em 28/02/2021

Publicado online em 12/03/2021 